\title{
Alternancia de pronombres en el habla de Bogotá
}

\section{Pronouns switching in Bogotá speech}

Pilar Mestre de Caro*

\author{
Recibido: 23 de julio de 2011 \\ Aprobado: 4 de noviembre de 2011
}

\section{Resumen}

Se estudian las formas de tratamiento usted, tú, vos y sumercé, fenómeno de coexistencia y alternancia de estos pronombres de segunda persona del singular en español, tanto en interacciones cotidianas como en medios masivos de comunicación, por medio de un enfoque microsociolingüístico que privilegia la metodología mediante el análisis pragmático de interacciones comunicativas, interpretadas a la luz de las teorías de J. Gumperz sobre la "alternancia de códigos" y cuyas reflexiones se fundamentan en las tesis de P. Trudgill y otros estudios sobre el contacto entre dialectos (P. Kerswill y D. Tuten). Se analizan las interacciones entre hablantes de diferentes dialectos de Colombia en Bogotá para mostrar que, a pesar de los valores canónicos de estos pronombres, usted y tú recubren valores pragmáticos similares a los del vous y tu en francés y el sistema alocutivo de Bogotá posee una cierta inestabilidad en el uso de estas formas. Así se puede aventurar la hipótesis de que la alternancia en el uso de los pronombres de segunda persona en Bogotá hace parte de un proceso koineizador que podría dar lugar a una nivelación para producir una nueva variedad dialectal en la que las alternancias de estos pronombres obedezcan tanto a una acomodación entre los interlocutores como a una forma de expresar la identidad plural y diversa de los hablantes que entran en contacto en esta ciudad.

Palabras clave: formas de tratamiento, contacto entre dialectos, pronombres de segunda persona, alternancia de pronombres.

\section{Abstract}

This article presents some aspects of the study of the pronouns of address in Spanish from Bogotá: usted, tú, vos and sumercé. Micro sociolinguistic approach is used through a qualitative study (radio and cinema conversations). We also analyze the pronominal form alternation, which consists in the switching from a pronoun to another in the same exchange, with the same interlocutor. These changes are interpreted through the analyses of J. Gumperz about the "code-switching". Our reflexions are also based on studies of P. Trudgill and others (P. Kerswill, D. Tuten), about "dialect contact". Interactions between speakers from various dialects of Colombia in Bogotá give evidence that in spite of the canonical uses of personal pronouns, where the usted and the tú overlay pragmatic values similar to the French vous and tu, the allocutionary system in Bogotá is moreover characterized by an instability in the use of these forms.

Key words: forms of address, dialect contact, second person pronouns, pronominal form alternation.

\footnotetext{
* Docente investigadora, Facultad de Educación, Universidad de La Salle. Correo: pmestre@unisalle.edu.co.
} 


\section{Introducción}

Las fórmulas y los términos de tratamiento son estructuras interiorizadas desde la infancia (costumbres verbales). El uso de estos mecanismos lingüísticos hace parte de las estrategias de cortesía verbal y depende del capital lingüístico y simbólico del hablante (Bourdieu, 1982), marcado por criterios y normas culturales de cada comunidad de habla. En el español de Bogotá se observa hoy en día un fenómeno de coexistencia y alternancia de los pronombres de segunda persona del singular (usted, tú, vos, sumercé), no solo en interacciones cotidianas familiares, sino también en aquellas difundidas a través de diferentes medios masivos de comunicación.

\section{Justificación}

Aunque la alternancia de los pronombres de segunda persona del singular es aún poco tratada en los estudios recientes sobre el español de Colombia, este fenómeno es ya destacado por investigaciones como la de Mary Edith Murillo Fernández (2003) sobre el "polimorfismo" en los deícticos de segunda persona en el habla de Popayán, y la de Ángela Bartens (2003), quien analiza el empleo de apelativos y pronombres personales en Bogotá. Puesto que se trata de un fenómeno que debe ser tenido en cuenta para la comprensión del español colombiano actual, en el presente artículo tratamos algunos casos que reflejan una fluctuación con respecto a los ejes vertical y horizontal de la interacción verbal. Mediante el análisis de las formas de tratamiento, presentamos algunos rasgos de la situación lingüística bogotana, en donde la disimetría y la alternancia en el uso de los pronombres de segunda persona manifiestan el carácter plural de los hablantes que allí interactúan.

\section{Enfoques teóricos}

La alternancia en el uso de los deícticos reside en el cambio de la forma de tratamiento dentro de un mis- mo intercambio comunicativo, ya sea dentro de un mismo turno conversacional o bien a lo largo de la conversación, con un mismo interlocutor (Mestre, 2010). Para comprender la alternancia del trato se ha adoptado la noción de alternancia en los deícticos de segunda persona, es decir, de tú, vos y usted, con base en los estudios sobre la alternancia de códigos (Gumperz, 1982) que, mutatis mutandis, permiten retomar las hipótesis de la alternancia metafórica y la alternancia situacional. Asimismo, la alternancia pronominal se explica desde la teoría de la acomodación (Giles y Ryan, 1982), ya que el uso de un pronombre determinado constituye un índice de la convergencia o de la divergencia hacia el interlocutor. Por otro lado, desde la pragmática se tienen en cuenta algunos aspectos constitutivos de la interacción verbal, como las estrategias de cortesía y los turnos conversacionales. Igualmente, los resultados que se presentan se apoyan en las investigaciones sobre contacto de dialectos (Montes, 1982; Trudgill, 1986; Tuten, 2003).

\section{El sistema de trato bogotano}

En el habla bogotana se utilizan fundamentalmente dos deícticos de segunda persona singular (usted y tú). Como lo ha señalado ya Diane Ringer Uber (1985) en su estudio sobre los pronombres de segunda persona en Bogotá, el tuteo y el tratamiento de usted adquieren valores pragmáticos inversos a los usos convencionales, presentando variaciones en los ejes de la distancia y la solidaridad. La expresión nominal familiar sumercé (forma apocopada de $s u$ merced) se encuentra también presente. Esta forma arcaica prevalece y es empleada, más que como un honorífico, como un término que connota afabilidad y solidaridad hacia el interlocutor. A pesar de ser una forma de tratamiento que porta una marca rural, el uso de este término no es exclusivo de personas mayores; por el contrario, los jóvenes lo han integrado también a su repertorio. 
Por su parte, el voseo es un tratamiento que se ha asociado a usos regionales específicamente (Carricaburo, 1997, p. 40); sin embargo, a pesar de ser una forma menos frecuente, se halla también presente. El uso del voseo en Bogotá se identifica desde comienzos de siglo XX, como lo muestra el escritor colombiano Eduardo Caballero Calderón, quien en una de sus obras describe algunos usos lingüísticos de los hablantes que vivían en la Bogotá de comienzos de siglo (1916-1924). En el siguiente ejemplo el autor evoca la forma como la abuela trataba a las personas de respeto, a la empleada (Mamá Toya) y a los nietos: "mi abuela deformaba voluntariamente o inconscientemente no sólo la gramática sino el vocabulario. A nosotros nos trataba de tú, de usted a las personas de respeto y a Mamá Toya de vos: vos querés, vos tenés, vos decís, cuando a nosotros nos decía tú quieres, tú tienes, y tú dices" (Caballero, 1994, p. 23). La reflexión de este novelista colombiano deja entrever una relación de jerarquía en el uso del voseo y del tuteo en Bogotá, pues mientras que el tuteo era reservado a los miembros de la familia, el voseo se empleaba como forma de tratamiento para los subalternos.

En nuestro estudio del español de Bogotá nos adherimos a la categorización realizada por el dialec- tólogo José Joaquín Montes Giraldo (1982). Dicha clasificación constituye una pauta para comprender mejor la diversidad geográfica y lingüística del país. De acuerdo con este autor, existen dos grandes dialectos en Colombia: el superdialecto costeño y el superdialecto central o andino. Teniendo en cuenta su clasificación se pueden asociar algunos pronombres de tratamiento a las zonas dialectales.

Como se observa en la tabla 1, los deícticos usted y tú pertenecen al dialecto andino oriental, correspondiente al español hablado en Bogotá. La expresión nominal su merced se incluye también dentro de este dialecto, con predominio en el departamento de Boyacá. No obstante, la clasificación realizada por José Joaquín Montes Giraldo no está planteada como un esquema rígido, sino que también tiene en cuenta la variación entre dialectos. Así, como veremos mediante de algunos de nuestros ejemplos, a pesar de que el voseo no es una forma de tratamiento característica del dialecto andino oriental, es plausible que se presente en algunas interacciones verbales en la capital. Con respecto a la situación lingüística diversa del país, Montes Giraldo afirma: "Por supuesto, en la realidad increíblemente variable y dinámica del habla hay que

Cuadro 1. Formas de tratamiento y zonas dialectales de Colombia

\begin{tabular}{|l|l|l|}
\hline \multirow{2}{*}{ Superdialecto } & Subdivisión & Pronombre o tratamiento que predomina \\
\hline \multirow{2}{*}{ Costeño } & Caribe & Tuteo de confianza \\
\cline { 2 - 3 } & Pacífico & Voseo en el trato igualitario o de confianza \\
\hline \multirow{2}{*}{ Central o Andino } & $\begin{array}{l}\text { Oriental } \\
\text { (Bogotá) }\end{array}$ & $\begin{array}{l}\text { Usted } \\
\text { Tú } \\
\text { Su merced (Boyacá) }\end{array}$ \\
\cline { 2 - 3 } & Occidental & $\begin{array}{l}\text { Vos } \\
\text { Tú }\end{array}$ \\
\hline
\end{tabular}

Fuente: Montes (1982, p. 57). 
contar con situaciones frecuentes, casi normales, de indeterminación o mezclas, de estados fluctuantes o mixtos que por unos aspectos pertenecen a un conjunto, por otros, a otro: el interdialecto o dialecto mixto es una realidad constante" (1982, p. 59). Por consiguiente, si la variación y el contacto de dialectos son característicos del español hablado en Colombia, es posible que las fluctuaciones en el sistema de formas de tratamiento reflejen estos fenómenos, ya que el movimiento de migración interna, así como el desplazamiento masivo de las zonas rurales y provincias a la capital son propicios a la interacción entre hablantes de orígenes y procedencias diferentes en Bogotá.

\section{Metodología: análisis de interacciones comunicativas}

Los pronombres y formas de tratamiento ameritan ser estudiados dentro de cada comunidad de habla, puesto que la variación de sus usos es una de las manifestaciones de la diversidad cultural en el mundo hispanohablante. Así, al interesarnos en el caso del español de Bogotá, se tiene como objetivo describir algunas situaciones de alternancia de pronombres de segunda persona del singular, que como se ha señalado ya en la introducción del presente artículo, constituye una estrategia discursiva presente tanto en interacciones comunicativas espontáneas, como en intercambios verbales difundidos a través de diferentes medios masivos de comunicación del país. En aras de señalar este aspecto, se ha privilegiado el análisis pragmático de interacciones comunicativas tomadas de espacios discursivos en los que se manifiesta y se recrea la cultura colombiana, como la radio y el cine. Esta clase de corpus resulta de especial interés para el presente estudio ya que se abordan como objetos socio-culturales que recrean y dan cuenta de los usos y de las representaciones lingüísticas que pueden identificar una comunidad de habla.
Los ejemplos de interacciones verbales que aquí se presentan hacen parte de un corpus de 270 minutos de interacciones verbales tomadas de filmes colombianos, así como de 180 minutos de intercambios difundidos a través de la radio de Bogotá. Se busca observar la manera en la que los interactantes hacen uso de la forma pronominal, ya sea a través de la radio, que como lo señala Patrick Charaudeau, es por excelencia el medio de comunicación "directo" y del "presente" (1997, p. 120), o también, en las ficciones cinematográficas, en las cuales los guionistas realizan un acercamiento etnográfico al vernáculo de los hablantes de una comunidad lingüística dada.

En la transcripción se conserva la sintaxis de la oralidad y se presentan en cursiva las fórmulas de tratamiento, así como los correferentes correspondientes. Las principales convenciones se describen a continuación:

Tabla 2. Convenciones de trascripción

\begin{tabular}{|l|c|}
\hline Participantes & $\begin{array}{c}\text { Sigla en mayúscula } \\
\text { seguida de: }\end{array}$ \\
\hline $\begin{array}{l}\text { Numeración de los turnos de } \\
\text { habla }\end{array}$ & $1,2,3 \ldots$ \\
\hline $\begin{array}{l}\text { Entonación ascendente, inte- } \\
\text { rrogación }\end{array}$ & $/$ \\
\hline Entonación descendente & 1 \\
\hline Interacción que continúa & $/ \ldots /$ \\
\hline Pausa corta & $\mid$ \\
\hline Pausa larga & | \\
\hline Comentarios & (texto) \\
\hline
\end{tabular}

\section{Corpus de entrevistas radiales}

Este tipo de corpus permite estudiar muestras auténticas de habla bogotana, por cuanto se trata de entrevistas transmitidas en directo. Son interacciones verbales que exigen continuidad y fluidez, de ma- 
nera que no hay una vigilancia discursiva total por parte de los participantes de la interacción. A continuación presentamos dos ejemplos de alternancia observados en la radio bogotana (2005), el primero de la emisora la W FM, que se dirige a un público adulto y el segundo de la Súper Estación 88.9, cadena radial para una audiencia joven.

- Interacción 1. Negociación del pronomBRE EN SITUACIÓN FORMAL DE COMUNICACIÓN:

En esta primera interacción se analiza una alternancia entre el tuteo y el tratamiento de usted por parte de un mismo hablante. Así, mientras que el periodista conductor del programa (JS) mantiene a lo largo del intercambio la forma usted, el entrevistado, un Senador de la República (SR), inicia su intervención empleando la forma tú y el nombre de pila del entrevistador, lo cual señala una disimetría respecto al uso de los pronombres y los términos vocativos en esta secuencia de la interacción verbal. (V. convenciones de trascripción al final del artículo).

(1) Corpus La W FM, Julio Sánchez (JS), senador Ramos (SR), 9-10:

I...।

9 JS: senador Ramos, está o no está nombrado su hijo| se ha vuelto a hablar del tema

10 SR: eh, Julio, un saludo muy cordial, y gracias por la oportunidad que me das para hacer una aclaración

Al continuar el intercambio, el entrevistado hace uso de la forma usted, además de utilizar la forma nominal don. De esta manera, el entrevistado replantea su posición frente al entrevistador y restablece el trato de usted simétrico:

(2) Corpus La W FM, Julio Sánchez (JS), senador Ra$\operatorname{mos}(S R), 25-28$ :
I.../

25 SR: eh, don Julio| el gobierno nacional desde hace tiempos quiso nombrarlo, pero eso quedó absolutamente claro en conversación con el señor presidente de la República| y yo entiendo que muchas veces esas noticias se le[s] pasa[n] a una... eh| [a] un noticiero tan importante como el suyo, a una emisora tan importante...

En otro turno conversacional, correspondiente a la secuencia de cierre del diálogo, llama la atención una nueva alternancia en el uso de los pronombres por parte de SR. Podemos notar que a lo largo de la entrevista este hablante pasa del tuteo (línea 10) al uso del usted (penúltima línea turno conversacional 25) y emplea finalmente un plural inclusivo (línea 75), que actúa como una estrategia verbal de cortesía.

(3) Corpus La W FM, Julio Sánchez (JS), Senador Ra$\operatorname{mos}(S R), 74-77$ :

74 JS: Senador| ¿va a Colombia Moda?/

75 SR: espero ir a Colombia Moda y espero que nos tomemos ahí un aguardiente, Julio

76 JS: así será, Senador, muchas gracias

77 SR: un saludo muy cordial

Por encontrarse en las secuencias de apertura y cierre de la interacción, los cambios en las formas de tratamiento observados en esta entrevista sugieren que la elección del pronombre personal es una operación lingüística compleja y que durante estos momentos puntuales de la comunicación el hablante negocia su imagen no solo frente al interlocutor, sino también frente a la situación de comunicación.

- Interacción 2. Reflexión Sobre el USO De USTEDEN COLOMBIA-88.9LASÚ PER ESTACióN:

Esta interacción del programa radial para jóvenes "El zoológico de la mañana" presenta el tratamiento 
disimétrico usted/tu, así como dos tipos de alternancia: tú/vos y tú/usted. Se trata de una entrevista realizada a un cantante argentino, quien emplea el tuteo y el voseo en sus turnos conversacionales. A pesar de alejarnos del marco de las interacciones estrictamente bogotanas, al analizar este corpus nos interesamos en las formas de trato que pueden variar en situaciones de contacto con extranjeros, así como en las estrategias de convergencia que los hablantes emplean para mostrar la empatía hacia un interlocutor que no comparte necesariamente el mismo uso del sistema alocutivo. De manera constante se encuentra que el locutor moderador, $\mathrm{CR}$, adopta y mantiene a lo largo de la comunicación la forma usted con el entrevistado, al igual que con los otros animadores de la emisión, un hombre (JM) y una mujer (LD), con quienes esta forma de tratamiento es recíproca. En cambio, el entrevistado, DT, inicia su turno conversacional respondiendo al entrevistador con la forma $t u$, que se mantiene a lo largo de toda la interacción con $\mathrm{CR}$ :

(4) Corpus 88.9, Diego Torres (DT), Capi Romero (CR), 12-13:

12 CR: Diego| bienvenido al Zoológico, un placer tenerlo con nosotros

13 DT: hola, Capi| qué tal| cómo estás| bien/

Otro locutor radial (JM), caracterizado por su sentido del humor y por desempeñar un papel más juvenil en el programa radial, comienza su intervención tuteando al entrevistado (turno de habla 36), dándole así una coloración mucho más informal al intercambio:

(5) Corpus 88.9, Jorge Marín (JM), Diego Torres (DT), 36-37:

36 JM: y mucho más si no tenías toda esa banda de diecisiete músicos que suena de una forma impresionante, sino únicamente $\underline{t u}$ guitarrita y $\underline{t u}$ voz o no/ /.../
37 DT: fue algo muy, muy impresionante no/ poder cantar esa canción ahí con la guitarrita, como vos decís

En la respuesta de DT (turno de habla 37) se observa el empleo del voseo, característico del trato solidario en Argentina. Por su parte, JM no se limita al uso del tuteo en su diálogo con el cantante argentino, sino que en otro turno de habla pasa del tuteo al voseo (línea 56) con DT. Este cambio puede ser comprendido como una estrategia de acomodación (convergencia) por parte del hablante bogotano, quien se moviliza hacia una forma de tratamiento recíproca con el entrevistado argentino, de esta manera establece una mayor cercanía. Al darse un uso simétrico del voseo, la interacción adquiere un matiz de complicidad y de jocosidad que dinamiza el diálogo entre estos dos interactuantes.

(6) Corpus 88.9, Jorge Marín (JM), Capi Romero (CR), Diego Torres (DT), 56-58:

56 JM: no sé, Diego, de pronto si tengás interés en hacer un dúo conmigol yo puedo cantar como Vicentico, eh [JM canta] no sé si te interese, eh, lo tenés en tus planes de pronto para los conciertos

57 CR: [risas]

58 DT: sí| vos tenés la misma panza que tiene Vicentico no/ /.../

En cuanto a la intervención de LD, la única mujer del magazín radial, en sus primeros turnos conversacionales emplea el tratamiento de usted (líneas 44-45) para formular las preguntas al entrevistado, quien por su parte adopta el tuteo para responderle (línea 47):

(7) Corpus 88.9, Lina Díaz (LD), Diego Torres (DT), 44-45:

44 LD: Diego| en $s u$ grabación de $\underline{s u}$ álbum $u n-$ plugged, ¿a qué otros artistas le hubiera gustado tener ahí a su lado, si hubiera tenido la 
oportunidad de invitar a otros artistas en $s u$ presentación?

45 DT: mirá| siempre ha quedado y tenemos como pendiente con Juanes hacer algo juntos.

Al final de la entrevista la locutora pasa del usted al tú (línea 93), para solicitarle a DT que permanezca en la línea para realizarle otras preguntas, ya no ante la audiencia, sino en privado:

(8) Corpus 88.9, CR (Capi Romero), Lina Díaz (LD), Diego Torres (DT), 90-93:

90 CR: pasamos a línea, pasamos a línea interna con Diego| qué iba a decir/

91 LD: hay unas cosas que le quiero preguntar a Diego internamente

92 CR: sí| sí, claro

93 LD: quédate ahí, por favor

Como se ve en el fragmento anterior, la mutación del usted al tú replantea la fuerza ilocutiva del acto de habla producido por LD (una petición). Se disminuye así el peso de la imposición que sería más fuerte al emplear la forma de tratamiento usted. Asimismo, teniendo en cuenta la teoría de la cortesía de Brown y Levinson (1987), el uso de "por favor" permite mitigar el FTA (Face-Threatening $A c t$ ) producido en la línea 93. Mediante uso del tuteo se establece, entonces, una mayor familiaridad, que equilibra el sistema de tratamiento de los dos interlocutores.

Para cerrar el análisis de esta interacción, otro aspecto que nos parece interesante resaltar es el comentario metadiscursivo de DT acerca del uso del pronombre usted en Colombia (turno conversacional 41). Se refiriere a una canción romántica que compuso con otro cantante argentino, titulada precisamente "Usted":
(9) Corpus 88.9, Diego Torres, 41:

41 DT: compusimos esta canción juntos los dos que decíamos usted, que es un homenaje a la mujer, y que estaba un poco inspirada no/ en esta cosa tan elegante que existe acá en Colombia| que se ha perdido en la mayoría de las partes de Latinoamérica| donde se habla de usted no/ /.../

Aquí el uso del adjetivo calificativo "elegante" refleja una actitud lingüística positiva hacia el empleo del usted, como forma solidaria de tratamiento en Colombia, por parte de un hispanohablante externo a esta comunidad de habla.

\section{Corpus cinematográficos}

En el estudio de la alternancia pronominal se han tenido también en cuenta diversas películas colombianas, con miras a estudiar variables sociolingüísticas tradicionales (edad, sexo, clase social) y para observar los contrastes que existen en el uso de la forma de segunda persona singular. En los ejemplos analizados a continuación nos centramos en la variable diastrática principalmente. Presentamos tres interacciones: una de la película María, llena eres de gracia (habla popular en Bogotá), y otras dos del filme Perder es cuestión de método (habla de clases sociales pudientes de Bogotá).

- Interacción 1. María, llena eres de gracia:

Por ser un filme en el que participan actores naturales, es viable estudiar el habla espontánea de Bogotá, así como algunos usos dialectales de locutores provenientes de diferentes partes del país, como en el caso de la secuencia puntual que analizamos en el ejemplo siguiente:

(10) Corpus camello, María (M) Franklin (F), 1-20:

1 F: vos bailás muy bacano 
2 M: si/ usted también

3 F: no pensé que la gente de por acá bailara tan bacano| yo pensé que eran todos más tiesos

4 M: y usted de dónde es de verdad/

5 F: yo soy de un pueblito que se llama Santa Rosa de Caball ahí como a diez minutos de Pereira| conocel

6 M: no

7 F: ahí hay unos termales rebacanos| un día de estos la invito

8 M: síl

9 F: oíste, y vos a qué vas a Bogotál

$10 \mathrm{M}$ : a Bogotá voy porque| yo tengo una amiga allá| ella trabaja en una casa de ricos y, pues, no sé| me va a ayudar

$11 \mathrm{~F}$ : [risas]

$12 \mathrm{M}:$ no| no se ría

13 F: no, no, qué pena| perdón| lo que pasa es que vos estás muy bonita como pa irte de sirvienta| pues muy mamacita pa disfrazarte así de gorrito y delantal y todo| no:

$14 \mathrm{M}$ : bueno, de todos modos, yol yo solo iba a ir a Bogotá como a mirar| pero no es nada seguro\}

$15 \mathrm{~F}$ : oístell si vos estás buscando trabajo, de pronto yo te puedo ayudar a conseguir un camellitol

16 M: un camellito/

17 F: es un camello que es viajando

18 M: viajando/ cuéntemel

19 F: es un trabajo de mula $\mid$ a mí me parece que es un trabajo bacano, porque usted val lleva lo que tiene que llevar| lo entrega le dan su billete y ya| todo sano /.../ yo conozco un man| el hombre organiza todo| los papeles| manda a la gente $\mid /$.../ sabés quél olvidémoslo| vamos

$20 \mathrm{M}$ : no| venga, espere| cuánto me pagarían por hacer eso

María es una joven de diecisiete años que trabaja en un cultivo de rosas. Pertenece a un medio social humilde y vive a las afueras de Bogotá. A lo largo de la película, María emplea la forma usted con la familia, el jefe y los amigos. El tuteo aparece solamente en un acto de habla, durante una escena en la que ella se dirige a un joven para decirle que su mejor amiga desea bailar con él: "ella quiere bailar contigo". Salvo este enunciado, el uso de usted es generalizado en el repertorio de esta hablante colombiana. Pero aunque la protagonista no alterna los pronombres, sí es un fenómeno presente en las interacciones que otros personajes entablan con ella, como en el caso del intercambio (10) sostenido con Franklin, joven originario del departamento de Caldas, en el quepredomina el voseo (dialecto andino occidental, según la clasificación ya citada de Montes Giraldo 1982; ver supra tabla 1). Este personaje se dirige a María utilizando de manera alternada el voseo y la forma usted. En cuanto a la historia conversacional de estos personajes, podemos decir que no hay mayor familiaridad entre ellos. Franklin conoce a María en una fiesta; posteriormente la encuentra por azar en el pueblo esperando el transporte público para ir a Bogotá. Este se ofrece para llevarla en su motocicleta y en el camino se detienen a tomar una bebida, entablando un diálogo en el que Franklin le propone a María trabajar como "mula".

En esta interacción, Franklin utiliza el voseo en cinco turnos conversacionales (líneas 1, 9, 13, 15, 19) y la forma usted en tres turnos solamente (líneas 5, $7,19)$. Por su parte, María mantiene el tratamiento de usted de manera constante (líneas 2, 4, 12, 18, 
20). Franklin emplea el voseo para marcar una cierta proximidad y familiaridad, mientras que pasa a la forma usted para responder a una pregunta personal (línea 5). Asimismo, en el turno conversacional 19 realiza un uso impersonal del usted, que podría ser explicado como una forma de restar importancia al peso de una proposición tan delicada como la que realiza este hablante a la joven. Al final de este turno conversacional, ante el silencio prolongado de María, Franklin pasa nuevamente al voseo. Cabe aquí anotar que en el registro popular colombiano, la expresión "sabés qué", acompañada de una entonación descendente, anticipa con frecuencia un comentario negativo o un insulto por parte del hablante que la emplea. Este uso podría, entonces, connotar el disgusto y un posicionamiento de superioridad por parte de Franklin hacia María, quien no acepta inmediatamente la propuesta.

Este intercambio permite ilustrar la diversidad de valores pragmáticos del voseo, forma de tratamiento que oscila entre la cercanía (turnos conversacionales $1,13,15)$ y el distanciamiento (turno de habla 19), de acuerdo con el contexto situacional y la intención comunicativa del hablante.

\section{- Interacción 2. Perder es Cuestión DE MÉTODO:}

Este filme del realizador colombiano Sergio Cabrera es una adaptación de la novela homónima del escritor contemporáneo bogotano Santiago Gamboa. Se trata de una historia enmarcada por el problema de la corrupción en la clase política del país. En esta parte analizamos los pronombres de tratamiento empleados por hablantes que se encuentran en una esfera social acomodada, con miras a ilustrar que la alternancia de trato puede presentarse en todas las clases sociales colombianas. El primer ejemplo corresponde a un altercado entre dos primos, uno concejal (Marco Tulio) y otro abogado (Emilio).
(11) Corpus Perder es cuestión de método - Marco Tulio Esquilache (MT), Emilio Barragán (EM), 11 15:

11 MT: y de dónde sacaste ese dato ahora/

12 EM: es que yo también me entero de vainas

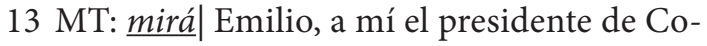
lombian Costruction me dijo que ya está listo todo el proyecto para la urbanización /.../

14 EM: no me digas que ya tienes un compromiso con ellos

15 MT: compromiso de qué| en qué país vives| en qué país vives tú| aterrizá, Emilio| quién crees que fue el principal aportante a mi campaña al concejol

Un primer aspecto que se observa en esta interacción es el empleo del tuteo entre los dos hablantes. Ciertamente, el tuteo en Bogotá es asociado a las clases sociales acomodadas, mientras que el tratamiento de usted se relaciona con las esferas sociales populares (como se aprecia, por ejemplo, en el habla de María). Esta característica la señala Catherine Travis (2002) en su estudio sobre el español de Bogotá, basado en muestras de novelas colombianas y conversaciones espontáneas grabadas en la capital en 1997. Con respecto a este fenómeno, ella afirma: "In considering the use of these forms in Bogotá, it is essential to first briefly address the sociolinguistics of their use. The lower social classes in Bogotá strongly favour usted, and tú is seen to be characteristic of higher social groups" (p. 173).

No obstante, y contrariamente a lo que se podría esperar, en los discursos de hablantes de una esfera social superior se da también la alternancia pronominal. De lo anterior se sigue que la alternancia del pronombre de segunda persona singular aparece en diversas esferas socioeconómicas y culturales de la capital. En el ejemplo de los políticos citado 
anteriormente, la alternancia reside en el paso del tuteo a la forma voseante dentro de un mismo turno conversacional (turno de habla 15). El paso al voseo toma aquí un valor de interjección, al presentar una forma imperativa, lo que produce un fuerte FTA (Face Threatening Act). Esta alternancia muestra igualmente un posicionamiento de superioridad por parte del hablante MT, quien realiza la mayoría de los cambios de tratamiento (líneas 13, 15), con lo que lidera el curso de la discusión.

Pasando ahora a la expresión nominal su merced, esta aparece con poca frecuencia en nuestros corpus de la radio y del cine. Se trata, sin embargo, de una forma de tratamiento que sigue siendo utilizada en Colombia, sobre todo en el registro familiar. Es posible escucharla entre personas mayores, así como entre jóvenes y adultos, que la emplean para manifestar el afecto e incluso con fines humorísticos. En este segundo ejemplo que proponemos, el uso de su merced es ilustrado de manera lúdica, al ser utilizado por un comerciante de esmeraldas poco escrupuloso (nuevo rico). La interacción de este fragmento gira en torno a la disputa entre el comerciante de esmeraldas y su amante (quien ha sido retenida y atada por los guardaespaldas de este), debido a la desaparición de un documento legal. El uso de su merced por parte de este personaje marca un indicio de la procedencia regional del hablante, pues, como ya se ha mencionado, predomina en Boyacá, departamento conocido también por su importante producción de esmeraldas.

(12) Corpus Perder es cuestión de método - Eleodoro (ED) Susana (SS), 11-15:

$11 \mathrm{~L}$ : devuélvame las escrituras, mamita, y festejamos| yo abro champaña y matamos caviar, y después a la camita| como siempre

12 SS: yo no las tengo, Eleodoro| te lo juro por Dios que yo no las tengo
13 EL: entonces, quién pudo haber sido/.../ seguro que sumercé no tiene nada que ver con ninguno de esos/

14 SS: que no\ tú eres mi socio| mi único socio| tú eres el mejor! papito

15 EL: elogio que se le agradece, pero de aquí nadie sale hasta que no aparezcan esas escrituras

En este corpus se halla una disimetría en el uso de los pronombres. Mientras que SS tutea a ED de manera constante, este, por su parte, alterna entre el trato de usted (línea 11) y la forma sumercé (línea 13). Desde el punto de vista de la prosodia, el tono de ternura utilizado en este enunciado puede indicar que se trata de una forma que el hablante utiliza para marcar la proximidad hacia su amante y persuadirla para que le diga la verdad. Al final de este intercambio (línea 15), ED evita el uso directo de un pronombre; solamente aparece como índice de tratamiento el clítico le, que presenta una ambigüedad en cuanto a la determinación del pronombre, ya que "le" es invariable en las dos formas, sumercé y usted. No obstante, es posible que corresponda al trato de usted de distanciamiento, puesto que ED rechaza el cumplido formulado por SS en el turno de habla precedente (línea 14) y profiere enseguida una amenaza (FTA) que cierra este diálogo del filme. Esta alternancia presentaría, entonces, una modificación del eje horizontal de la interacción, lo que aumenta la distancia entre los participantes.

Los porcentajes de empleo obtenidos a partir del número de ocurrencias de cada forma de tratamiento describen una tendencia en la cual el sistema alocutivo está centrado en los pronombres usted y tú fundamentalmente. La forma pronominal usted ocupa un lugar más importante en comparación con el tú. Las otras formas de tratamiento presentan valores poco representativos con respecto al binomio T/V. Por ejemplo, el pronombre vos obtiene $13 \%$ en 
Tabla 3. Resumen cuantitativo del uso de la forma pronominal en los ejemplos de interacciones en filmes y emisoras de radio

\begin{tabular}{|l|c|c|c|c|c|c|}
\hline \multirow{2}{*}{$\begin{array}{c}\text { Corpus filmes } \\
\text { y radio }\end{array}$} & \multicolumn{6}{c|}{ Formas de tratamiento } \\
\cline { 2 - 7 } & Usted & Tuteo & Voseo & Sumercé & $\begin{array}{c}\text { Alternancias de } \\
\text { pronombres }\end{array}$ & $\begin{array}{c}\text { Total } \\
\text { pronombres }\end{array}$ \\
\hline María, Ilena eres de gracia & 26 & 28 & 11 & 0 & 7 & 72 \\
\hline Perder es cuestión de método & 2 & 20 & 2 & 2 & 3 & 29 \\
\hline Corpus Diego Torres & 7 & 8 & 4 & 0 & 2 & 21 \\
\hline Corpus Senador Ramos & 11 & 1 & 0 & 0 & 1 & 13 \\
\hline Total general de ocurrencias & $\mathbf{4 6}$ & $\mathbf{5 7}$ & $\mathbf{1 7}$ & $\mathbf{2}$ & $\mathbf{1 3}$ & $\mathbf{1 3 5}$ \\
\hline Porcentaje & $34 \%$ & $42 \%$ & $13 \%$ & $1,4 \%$ & $9,6 \%$ & $100 \%$ \\
\hline
\end{tabular}

los resultados de estos corpus. La forma sumercé, por su parte, presenta un porcentaje de $1,4 \%$, lo que la ubica igualmente como una forma de tratamiento esporádica (tabla 3), a pesar de continuar vigente e incluso ir en aumento, como lo señalan, por ejemplo, Javier Guerrero y Néstor Pardo:

El sumercé en la actualidad es un fenómeno de interés lingüístico y sociolingüístico en tanto que su uso no se puede considerar residual ni marginal, sino que, por el contrario, gana prestigio, pues es usado por sectores influyentes en la sociedad y empieza a verse en ámbitos élite como los medios de comunicación. Esto se demuestra en su uso más allá del ámbito familiar y privado, y en la extensión a lo público y cotidiano como se puede fácilmente constatar en entidades públicas, en los servicios de atención al usuario, en los medios de comunicación (telenovelas), o por parte de reconocidos e influyentes personajes como la cantante de rock Andrea Echeverri de la banda Aterciopelados, y el presentador de televisión y cronista Pirry, entre otros (2012, pp. 211-218).

En cuanto a las alternancias de pronombres, estas representan el 9,6\% de los usos constatados en las interacciones verbales y se posicionan como prácticas lingüísticas aleatorias en el seno de las conversa- ciones. Por consiguiente, a pesar de tratarse de una característica observable en el habla bogotana, es necesario el desarrollo de nuevos estudios de corte longitudinal, con el ánimo de explorar si el fenómeno de la alternancia pronominal conllevaría un posible cambio lingüístico.

\section{Conclusión}

Mediante los intercambios verbales analizados se pone en evidencia la diversidad en los usos de la forma pronominal en Bogotá y la presencia de la alternancia en el uso de los pronombres. De esta manera, al tener en cuenta el origen diverso de los hablantes que interactúan hoy en día en la capital, es posible plantear la hipótesis de que la alternancia en el uso de los pronombres de segunda persona en Bogotá hace parte de un proceso koineizador que posiblemente dará lugar a una nivelación para producir una nueva variedad dialectal en la que las alternancias en los usos de los pronombres de segunda persona obedezcan no solamente a una acomodación entre los interlocutores, sino también a una forma de expresar la identidad plural y diversa de los hablantes que entran en contacto en esta ciudad. 
La variable diatópica se convierte, entonces, en un factor relevante en la expansión de la diversidad lingüística, tal como lo señala Peter Trudgil: "la difusión geográfica de las formas lingüísticas ocurre, en su mayoría, cuando la interacción cara a cara entre hablantes de diferentes áreas ocurre con suficiente frecuencia como para que la acomodación se vuelva permanente y en una escala suficientemente importante para que un número considerable de hablantes se vea envuelto" (1986, p. 42). ${ }^{1}$ De esta manera, formas de tratamiento que estaban reservadas en un comienzo a una sola región se vuelven funcionales en el contexto urbano, donde los hablantes hacen uso de formas regionales, aprendidas posiblemente en el ámbito familiar, que paulatinamente se extienden a otros contextos conversacionales, gracias a las prácticas de la oralidad.

Los ejemplos analizados en el presente artículo sugieren que la alternancia de pronombres de segunda persona del singular se ha integrado a las interacciones cotidianas de hablantes colombianos, tanto en los medios masivos de comunicación (radio) como en las representaciones lingüísticas (filmes). Este es un fenómeno que puede presentarse en diferentes esferas sociales, en situaciones de comunicación tanto formal como informal. Asimismo, la alternancia de formas de tratamiento está ligada a factores interaccionales (cambios en el estado de ánimo del hablante) y a situaciones de contacto entre dialectos.

Los cambios del pronombre de segunda persona del singular modifican la relación entre interactantes, dependiendo de la situación de comunicación, el grado de formalidad y el contenido discursivo. Asimismo, aunque existen valores pragmáticos y sociales asignados de manera convencional al empleo de las diferentes formas de tratamiento (usted de respeto, tuteo de confianza, voseo de familiaridad o de desprecio, su merced de afecto), nuestros datos indican que el valor ilocutivo de estos términos no está predeterminado, sino que su función se construye en el seno de la interacción comunicativa.

Como estrategia verbal, la alternancia del pronombre de segunda persona del singular actúa como reguladora de los ejes de solidaridad y de distanciamiento. Gracias a este recurso discursivo los hablantes pueden modificar y replantear los papeles desempeñados a lo largo del intercambio verbal. Esta diversidad de usos puede ser comprendida, entonces, como una variación de estilo y una forma de polifonía discursiva que hace parte del habitus lingüístico (Bourdieu, 1982) de los hablantes que interactúan en la capital colombiana.

\section{Reconocimientos}

El artículo divulga los principales resultados de la investigación: "Pronombres de segunda persona: dinámicas de su empleo en el español de Bogotá', avalada por la Universidad René Descartes de Paris 5, Facultad de Ciencias Humanas de la Sorbona.

\section{Bibliografía}

\section{Películas}

Mezey, P. (prod.) y Marston, J. (dir.) (2004). María, llena eres de gracia. Colombia-Estados Unidos: HBOfilms.

Goldenber, J. (prod.) y Cabrera, S. (dir.) (2005). Perder es cuestión de método. Colombia-España: Tornasol Films.

1 "The geographical diffusion of linguistic forms takes place, for the most part, when face-to-face interaction between speakers from different areas happens sufficiently frequently for accommodation to become permanent and on a sufficiently large scale for considerable numbers of speakers to be involved". 


\section{Emisiones radiales}

Emisora La WFM. La W de Julio Sánchez Cristo. Abril de 2005, Bogotá.

Emisora 88.9. El zoológico de la mañana. La Súper Estación, mayo de 2005, Bogotá.

\section{Bibliografía científica}

Bartens, A. (2003). Notas sobre el uso de las formas de tratamiento en el español colombiano actual. Coloquio Pronoms de 2 personne et formes d'adresse dans les langues d'Europe, 7 y 8 de marzo, Instituto Cervantes, Centro Virtual Cervantes, París. Recuperado de:

http://cvc.cervantes.es/obref/coloquio_paris/ ponencias/bartens.htm

Bourdieu, P. (1982). Ce que parler veut dire. París: Fayard.

Brown, P. y Levinson, S. (1987). Politeness. Some universals in language usage. Cambridge: Cambridge University Press.

Caballero, E. (1994). Memorias infantiles. Bogotá: Panamericana.

Carricaburo, N. (1997). Las fórmulas de tratamiento en el español actual. Madrid: Arco.

Carricaburo, N. (2010). "El ustedeo, un fenómeno que avanza en la Argentina”. En: Formas y fórmulas de tratamiento en el mundo hispánico. México D. F. El Colegio de México, Centro de Estudios Lingüísticos y Literarios. Graz, Austria: Karl-Franzens Universität Graz.

Charaudeau, P. (1997). Le discours d'information médiatique. París: Nathan.

Guerrero, J. y Pardo, N. (2012). La fórmula de tratamiento "sumercé": una aproximación prelimi- nar desde la sociolingüística. En El lenguaje en Colombia Realidad lingüística de Colombia (t. I). Bogotá: Instituto Caro y Cuervo-Academia Colombiana de la Lengua.

Giles, H. y Ryan, E. (eds.) (1982). Attitudes towards language variation: Social and applied contexts. Londres: E. Arnold.

Gumperz, J. (1982). Discourse strategies. Cambridge: Cambridge University Press.

Mestre de Caro, P. (2008). Pronoms de deuxième personne: dynamiques d'emploi en espagnol de Bogota. (Tesis Doctoral en Ciencias del Lenguaje, dir. Christine Deprez) Universidad de París Descartes.

Mestre de Caro, P. (2012). Formas de tratamiento en el habla bogotana: ¿Hacia un replanteamiento de los usos canónicos de los pronombres de segunda persona del singular? En $L a$ oralidad en contextos diversos. Aportes investigativos para su discusión y comprensión. Bogotá: Kimpres.

Mestre de Caro, P. (2010). Alternancia de formas de tratamiento como estrategia discursiva en conversaciones colombianas. En Formas $y$ fórmulas de tratamiento en el mundo hispánico. México: El Colegio de México, Centro de Estudios Lingüísticos y Literarios. Graz, Austria: Karl-Franzens Universität Graz.

Montes, G., J. (1982). Dialectología general e hispanoamericana. Orientación teórica, metodológica y bibliográfica. Bogotá: Instituto Caro y Cuervo.

Murillo, F., M. (2003). El polimorfismo en los pronombres de tratamiento del habla payanesa. (Coloquio Pronoms de 2 personne et formes 
d'adresse dans les langues d'Europe, 7 y 8 de marzo) Instituto Cervantes, Centro Virtual Cervantes, París. Recuperado de: http://cvc. cervantes.es/obref/coloquio_paris/ponencias/ murillo.htm

Pardo, N. y A. Ramírez, S. (2010). Norma categorial para el español de Bogotá Colombia. Folios, 32 (segundo semestre).

Travis, C. (2002). La metalengua semántica natural: The Natural Semantic Metalanguage of Spanish. En C. Goddard y A. Goddard (eds.),
Meaning and universal grammar - Theory and empirical findings (1). Amsterdam y Philadelphia: John Benjamins.

Trudgill, P. (1986). Dialects in contact. Oxford: Basil Blackwell.

Tuten, D. (2003). Koineization in Medieval Spanish. Berlin: Mouton de Gruyter.

Uber, D. (1985). The dual function of usted: Forms of address in Bogotá, Colombia. Hispania, 68 (2), 388-392. 